\title{
Introduction: Insurance and Business Ethics
}

\author{
Aaron Doyle
}

Published online: 10 February 2012

(C) Springer Science+Business Media B.V. 2012

The study of the specific problems of insurance ethics remains relatively undeveloped, either from sociological or business ethical perspectives. More recently, sociologists and socio-legal scholars have given a sustained new wave of attention to insurance (see, e.g., Baker and Simon 2002; Baker 2010; Ericson et al. 2003; Doyle and Ericson 2010) while the particular problems of insurance ethics have also received fresh scrutiny (see, e.g., Flanagan et al. 2007). These disciplinary approaches begin to meet in the collection of articles in this special issue, which examine diverse contexts and dimensions of insurance business ethics at both empirical and normative levels.

Insurance arrangements are very important to consider from an ethical perspective, as they not only reconfigure risk but also reshape ethical responsibilities (Baker 2002; Brinkmann 2005). As Turo-Kimmo Lehtonen and Jyrri Liukko explore in their article in this special issue, private insurance creates an important kind of social solidarity among those in the risk pool, although this solidarity is not necessarily evident to or understood by the insured; such solidarity was perhaps clearer to participants in early forms of insurance featuring small pools of people in relatively closely knit communities sharing risks, compared to the much vaster and more institutionally complex forms that insurance often takes today. Yet, insurance remains a crucial element of the contemporary social fabric, though this may be taken for granted by many, and is perhaps most evident to those who cannot afford adequate coverage. Indeed, micro-insurance in developing countries, as discussed by Ralf Radermacher and Johannes Brinkmann in

\footnotetext{
A. Doyle $(\bowtie)$

Department of Sociology and Anthropology,

Carleton University, Ottawa, ON, Canada

e-mail: aaron_doyle@carleton.ca
}

their article, represents something of a return to the historical communitarian roots of insurance. On the other hand, several of the articles in this volume might be seen as beginning to suggest that the core values that were more easily evident in early, simpler forms of insurance may have sometimes become corroded as a result of the contemporary ways in which insurance is now organized. For example, Bill Lesch and Johannes Brinkmann raise important questions in their article about the responsibility of insurers as co-contributors to problems of insurance fraud.

It is also important to note also that insurance ethics is not just about insurance: insurance also governs (Ericson et al. 2003) and reshapes responsibility among insured individuals and organizations in a huge variety of other social and institutional settings, for example, playing a crucial role in the evolution and direction of tort law as Christian Lahnstein argues in his piece, or facilitating risky technological megaprojects like the ill-fated Deepwater Horizon oil venture in the Gulf of Mexico, as Alexandros Kyrtsis examines in his article.

Gathered at the world headquarters of Munich Re, near the famous English Gardens in Munich, for 2 days in February 2011, a small and interdisciplinary group of academics and insurance professionals from seven countries grappled with ethical questions in diverse contexts of the world of insurance. The articles that make up this special issue were all presented at that workshop. The remainder of this short introduction gives a quick overview of the issues that are addressed in each article, and then briefly ends with a call for dialog and future work to start to distill more general principles of insurance business ethics.

The articles that follow are wide-ranging but can be broadly situated in three groups. A first group of articles addresses the particular ethical challenges facing different 
professional or occupational groups in the insurance field such as actuaries, lawyers, and marketers. A second group of articles addresses how the insurance industry shares and helps allocate ethical responsibility for particular social problems, such as major technological projects, and global poverty and sustainable development; the industry's role in the causes of and solutions to the problem of insurance fraud is also scrutinized. A third group of articles interrogates questions of values and ethics at the core of insurance relationships: trust versus mistrust in insurance contracts, and what equality, discrimination, and solidarity actually mean in insurance risk pools.

One way of developing the field of insurance ethics is to look at the challenges facing particular kinds of insurance professionals. The article in this issue by Nicos Scordis contributes an ethics of risk modeling. As Scordis explains, "risk modeling" refers to the use of quantitative techniques to simulate hundreds of possible outcomes resulting from a managerial decision under a variety of interlocking assumptions. These hundreds of outcomes may then be summarized in a probability distribution graph that shows the financial consequences of the managerial decision. As Scordis explains, a risk modeling culture has evolved where the apparent exactness of pure mathematics is preferred to the imprecision of human behavior. As a result of this culture, such risk models tend to present a veneer of certainty in relation to their own accuracy that is not always justified, a tendency in insurance more generally (cf. Ericson and Doyle 2004). This over-confidence about risk modeling had profound consequences in contributing to the recent financial crisis, Scordis argues. In response to such problems, ethical codes for responsible risk modeling have been proposed. Scordis argues that a critical evaluation of the risk modeling process suggests that ethical judgments are emergent rather than static, vague rather than clear, and particular rather than universal. Thus, positive moral guides that provide explicit instructions for responsible behavior are of limited practical value. Instead, Scordis argues, Aristotle's classical virtue of "prudence" provides a framework for critical evaluation of current risk modeling practices, and a focus for the development of alternatives to the current practices that make models underestimate risk. Using examples, Scordis identifies five characteristics of prudent risk modeling. A prudent risk modeler, he argues, recognizes that people behave according to the particular ways in which economic incentives affect them, which means that identical assets, in terms of cash flow, may in fact have different valuesdepending on who holds them. A prudent risk modeler recognizes that all existing measures do a poor job in capturing interactions among risks, a critical component of risk models. A prudent risk modeler uses risk metrics that resonate with the way people think and feel about risk. A prudent risk modeler allows the questions posed by management to determine the scope of the model so that the model becomes a tool for helping managers understand uncertainty. Finally, a prudent risk modeler makes clear the consequences of decisions when the results of the model deviate from reality. Thus, Scordis offers an important set of ethical guidelines for risk modeling.

In addition to actuaries, lawyers represent a second key occupation in the insurance world, and insurance profoundly shapes the development and practice of law. Christian Lahnstein, an insurance lawyer, head of the Department of Risk, Liability and Insurance at Munich Re and host of the seminar, gave the academics gathered in Munich a number of insights from the point of view of a professional with a global view concerning the complex questions that arise due to the interactions in the intricate "chicken and egg" relationship between liability insurance and tort law (see also Baker 2005; Abraham 2008). For example, as Tom Baker and Sean Griffith have pointed out, the existence of director's and officer's liability insurance in the United States drives and thoroughly shapes shareholder litigation in that country (Baker and Griffiths 2007). Without liability insurance, tort law in that area would be something completely different. Lahnstein encourages and moves toward making explicit and examining the normative questions that arise due to the tort law-liability insurance interaction. He encourages liability insurers to rethink and be more aware of their own role and responsibility in actively shaping tort law. Lahnstein builds on previous discussions of the tort law-liability insurance interaction in part by introducing discussion of this relationship in the developing world. He argues that insurers can play an active role in helping tort law evolve in socially beneficial ways in emerging markets in the developing world, and that this role, and the aim of developing tort law in a positive fashion, should be openly acknowledged so that insurers can approach these responsibilities in a careful and thoughtful way.

A second way of developing the field of insurance ethics focuses on the key role of insurance in reshaping risk and responsibility sharing in a broad variety of social and institutional contexts. Alexandros-Andreas Kyrtsis, from the University of Athens, discusses the responsibilities of insurers in relation to large scale technological projects, using the example of the explosion of the Deepwater Horizon oil drilling platform in the Gulf of Mexico. Kyrtsis argues that the accident in April 2010, and the resulting massive oil spill, were not due to any natural phenomena, but to unsound technological decisions and ethically questionable managerial practices. Politicians and state authorities apparently failed to prevent such misconduct. But what about the insurance industry, which also suffered significant losses from this disaster? Should they not also 
be interested in preventing catastrophic developments, and thus simultaneously acting for the benefit of the public and of the natural environment? Kyrtsis argues that insurers should connect their policies with looking more closely at the internal procedural ethics of organizations, and puts forth that, through the operation of appropriate procedural ethics, insurance can be an institutional driver toward sound operational risk management. Unethical behavior in sensitive operational settings originates from a lack of sufficient esteem for staff responsible for procedural efficiency. Insurance policies for such massive and risky projects should entail screening and monitoring of likely sources of such difficulties. Conditions are ripe for such innovations in the insurance industry, Kyrtsis suggests; the stories we get from insurers and managers, who had to reflect on the causes of such disasters, show that there is enough awareness for this necessity. It remains to make them talk openly about their concerns and transform their thoughts into appropriate business practices.

Another possible area for the industry to show leadership is in promoting and supporting micro-insurance initiatives in the developing world. Ralf Radermacher from the Micro-insurance Academy in New Delhi and Johannes Brinkmann from the BI Norwegian Business School argue that the societal responsibility of insurance becomes easier to explain and understand in smaller, simpler, less developed communities, which can be helped very significantly with micro-insurance. Micro-insurance offers basic coverage for a small premium to poor and vulnerable populations - typically (but not necessarily always) in developing countries. Examples of micro-insurable risks are health, death, crop failure, and property loss. Micro-insurance uses the same technology of sustainable pool construction as conventional insurance-but to work effectively, its operations need to maximize simplicity, accessibility, affordability, and flexibility. Their paper highlights how microinsurance offers a way of rediscovering the historical roots of insurance based in mutual aid in small, closely knit communities. However, the ethical riskiness of insurance marketing increases with the vulnerability of its customers, meaning there is a special set of problems with microinsurance. How might one ethically target the poor as a market? To help answer these questions, Radermacher and Brinkmann promote the importance of practically based research based in actual working micro-insurance projects. They suggest dialog and action research as interdependent next steps for building an ethics of micro-insurance.

Bill Lesch from the University of North Dakota and Johannes Brinkmann from the BI Norwegian Business School offer a novel and important perspective on the question of insurance fraud. Lesch and Brinkman aim to provide a starting point for understanding the current motivations and practices by both insurers and fraud which result in market inefficiencies due to cheating and bad faith, and to outline ways in which society can begin to repair what have become expensive, and unethical practices around insurance fraud which appear to be in a permanent and harmful spiral. In media coverage, and when the insurance industry talks about it, insurance abuse is first identified by its worse cases, involving organized insurance fraud, and then presented in an oversimplified "blame and shame" mode, where the insurance customers are the villains, while the insurance industry is the hero, fighting on the side of the honest customers. However, as research discussed by Lesch and Brinkmann shows, many insurance customers rationalize insurance abuse in blaming and shaming terms, too, suggesting that the industry is cheating them; thus it may be argued that insurers get the abuse and the cheating they deserve. Lesch and Brinkmann urge that both sides need to recognize that consumers and insurance companies have co-created this environment, and are coresponsible for it. Neither operates in isolation from the other, and both parties must be willing to recognize today's occasional dysfunctional patterns of behavior in relation to insurance fraud for what they can be: destructive to the concept of insurance and harmful to the ideals of a society predicated on solidarity. As Lesch and Brinkman see it, the interesting question is: in what ways could everyone address insurance abuse more constructively (and avoid a vicious cycle of blaming and shaming which destroys insurance's potential as a means of creating community)? Insurance marketing is ideally about find the place where companies meet their customers in order to maximize joint benefits, or, as it is called in modern marketing theory, cocreation of value. A key point is that it takes two parties to create value and that it takes two parties to destroy it.

One can also develop an understanding of insurance ethics by starting out from various typical ends values, such as security or sustainable development, or means values such as solidarity, or fair distribution of rights and duties, or trust. The task can then be seen as: to isolate and then elaborate indispensable basic values or principles, as the foundation or key to successful insurance technologies and insurance relationships. Two of the articles here can be understood as helping build such a framework.

Two sociologists from the University of Helsinki, TuroKimmo Lehtonen and Jyri Liukko, deal with a different set of challenges for insurers and for those interested in understand insurance ethics: the challenges of defining what constitutes equality and discrimination in the insurance context. They argue that insurance can be thought of as producing what sociologists call "solidarity" among everyone in a risk pool, so that those in the pool become a community of people sharing risk. What makes insurance special is the particular way in which it links solidarity and discrimination. Insurance has a built-in connection to 
solidarity: when becoming insured, one participates in a risk pool within which each member is responsible for others' risks. The combination of technical efficiency and group solidarity made insurance a successful tool for government in welfare societies during the twentieth century. On the other hand, private insurance especially is very often based on inequality as it discriminates between insured's by classifying them into different risk groups. This results in different prices on the basis of such risk factors as age, gender, health, and disability. In some cases, the practice of discrimination leads to the total exclusion of some people from insurance coverage. From the point of view of business ethics, however, it is interesting that the connection between insurance and solidarity is not limited to social welfare and social insurance, but is also evident in relation to private insurance as well. At the same time, however, it is important to understand that insurance creates very particular kinds of solidarity. The main questions the Finnish sociologists ask then are: What does solidarity mean in different insurance situations? How are the limits of solidarity defined and justified?

A very interesting example is the decision, in March 2011, by the European Court of Justice to ban insurance discrimination on the basis of gender. The prohibition of this widespread underwriting practice represents a radical shift toward a new conception of equality and solidarity between women and men in the world of insurance. Requiring equal prices for both sexes creates what these sociologists call "subsidizing solidarity" toward men, in life insurance for example. Until now, men have been paying more for their life insurance policies because on average, they die earlier than women. From now on, being a woman will no longer be allowed to form a separate risk category; women cannot benefit from causing less risk than men for the whole risk pool. The ethical and sociological questions raised by this shift are profound-on what bases is it justified to discriminate then? It might be argued that men should pay more for automobile insurance, because the fact they have a higher rate of accidents than women is the result of their more risky driving style. What about paying more for life insurance? How much is the shorter life expectancy of men a result of their own choices? Such questions will be very topical in the aftermath of the decision by the European Court of Justice prohibiting different risk rating by gender.

It has been said that if there is trust there is no need of a precise contract, and if there is mistrust a precise contract will not help either. If one assumes that the fine print in an insurance contract communicates mistrust, then one risks that such mistrust becomes contagious and mutual. Øyvind Kvalnes, BI Norwegian Business School, addresses the insurance industry's practice of producing lengthy insurance contracts, with much fine print stating the minute details of the circumstances under which the insurance does and does not apply. While the fine print problem is by no means limited to the world of insurance, the insurance industry has become something of a "poster child" for this more general problem (Stone 2002). Kvalnes discusses whether the use of such extensive fine print might often represent a counter-productive incentive for customers. His reasoning is structured like this: Insurance sales and advertising make general promises and create expectations of security and coverage, from the insurer to the insured, and communicate implicitly that the insurer should be trusted to assist the insured appropriately in case of a negative event. On the other hand, insurance contracts and policies limit rather than elaborate the expectations created by the advertising promises. The original trust relationship is risked when the content of the promise is restricted in unexpected ways by the contract, which typically contains clauses and conditions that the consumer is unaware of. Kvalnes' contribution proceeds in four steps, looking at (1) the sources of the fine print policy practice, (2) at its immediate effects on the understandability of the policies for the insured, (3) at the ethicalness of restricting the content of the insurer's promise to the insured, in ways which may often be unexpected, and then suggesting (4) the measures that insurers might take for developing a more constructive and ethical relationship with their customers (cf. the article by Lesch and Brinkmann in this special issue).

To conclude briefly, insurance is a highly distinctive and centrally important social institution, which thus needs a distinctive business ethics. The articles presented here together represent a significant step toward addressing this need. They allow us to begin to draw out some of the general themes that need to be addressed in advancing insurance business ethics, for example: clear communication with the consumers about the promises, certainties and uncertainties of insurance, in order to foster a virtuous circle of trust between company and consumer; acknowledgment of the limits of risk modeling for insurers and recognition of ways of prudently dealing with those limits; understanding insurance's role in producing and reproducing social solidarity as more than just another business; clear articulation of general principles governing when discrimination might be justified in risk rating; and acknowledgment of and responsible management of insurance's effects in reshaping risk and responsibility in countless social and institutional settings around the globe. The hope is that the articles in this issue will generate dialog that will move us further toward building such an ethics of insurance.

Acknowledgments The editor wishes to thank Munich Re, the Norwegian Research Council's Societal Security and Risk (SAMRISK) 
programme and the Centre for Risk and Insurance Research (ROFF) at BI Norwegian Business School for supporting the workshop that led to this special issue.

\section{References}

Abraham, K. S. (2008). The liability century: Insurance and tort law from the progressive era to 9/11. Cambridge: Harvard University Press.

Baker, T. (2002). Risk, insurance and the social construction of responsibility. In T. Baker \& J. Simon (Eds.), Embracing risk: The changing culture of insurance and responsibility. Chicago: University of Chicago Press.

Baker, T. (2005). The view of an american insurance law scholar: Six ways that liability insurance shapes tort law. In G. Wagner (Ed.), Tort law and liability insurance. New York: Springer.

Baker, T. (2010). Insurance in socio-legal research. Annual Review of Law and Social Science, 6, 433-447.

Baker, T., \& Griffiths, S. J. (2007). The missing monitor in corporate governance: The directors' \& officers' liability insurer. Georgetown Law Journal, 95, 1795-1842.
Baker, T., \& Simon, J. (Eds.). (2002). Embracing risk: The changing culture of insurance and responsibility. Chicago: University of Chicago Press.

Brinkmann, J. (2005). Understanding insurance customer dishonesty: Outline of a situational approach. Journal of Business Ethics, 61, 183-197.

Doyle, A., \& Ericson, R. (2010). Five ironies of insurance. In G. Clark, G. Anderson, C. Thomann, \& J. M. Graf Von Der Schulenburg (Eds.), The appeal of insurance (pp. 226-247). Toronto: University of Toronto Press.

Ericson, R., \& Doyle, A. (2004). Uncertain business: Risk, insurance and the limits of knowledge. Toronto: University of Toronto Press.

Ericson, R., Doyle, A., \& Barry, D. (2003). Insurance as governance. Toronto: University of Toronto Press.

Flanagan, P., Primeaux, P., \& Ferguson, W. (Eds.). (2007). Insurance ethics for a more ethical world. New York: Elsevier.

Stone, D. (2002). Beyond moral hazard: Insurance as moral opportunity. In T. Baker \& J. Simon (Eds.), Embracing risk: The changing culture of insurance and responsibility. Chicago: The University of Chicago Press. 